Research Article

\title{
Adolescent Boys Workshops: Creating Awareness on Various Boys Issues in a Slum and Resettlement Colony in Delhi
}

\author{
Sayantan Banerjee', Joyce F Vaghela ${ }^{2}$ \\ ${ }^{1}$ GDMO, Community Health Department, St. Stephen's Hospital, Delhi, India. \\ ${ }^{2}$ Head of the Department, Community Health Department, St. Stephen's Hospital, Delhi, India. \\ DOI: https://doi.org/10.24321/2349.2880.201915
}

\section{I $\quad \mathbf{N} \quad \mathbf{F} \quad \mathbf{O}$}

\section{Corresponding Author:}

Sayantan Banerjee, Community Health Department, St. Stephen's Hospital, Delhi, India. E-mail Id:

banerjeesayantan08@gmail.com

Orcid Id:

https://orcid.org/0000-0001-5701-2625

How to cite this article:

Banerjee S, Vaghela JF. Adolescent Boys Workshops: Creating Awareness on Various Boys Issues in a Slum and Resettlement Colony in Delhi. Ind J Youth Adol Health 2019; 6(4): 1-5.

Date of Submission: 2020-05-04

Date of Acceptance: 2020-05-24

\section{$\begin{array}{llllllll}\mathbf{A} & \mathbf{B} & \mathbf{S} & \mathbf{T} & \mathbf{R} & \mathbf{A} & \mathbf{C} & \mathbf{T}\end{array}$}

Background: Adolescence is the period of growing-up, this phase is characterized by marked and rapid changes: physical, psychological, sexual, socio-economical. There are many workshops and training sessions held for adolescent girls, while the boys in this age group are overlooked. The present study focuses on a series of workshops that were held exclusively for adolescent boys in an urban resettlement colony in Delhi.

Method: This retrospective study was conducted from $15^{\text {th }}$ February 2020 to $15^{\text {th }}$ May 2020, in a slum community of Delhi, for 131 adolescent boys, who had attended Adolescent Boys Workshops from February to August 2019. The study was aimed to find out the increase in the awareness and knowledge of adolescent boys who attended these workshops, on various adolescence related topics. Statistical analysis was done in order to obtain mean, median and mode of the test scores. The student $T$ test was applied to find the statistically significant $p$ value. A $p$-value $<0.05$ was taken as significant.

Result: There was increase in the mean knowledge score from 5.3 to 7.0; $\mathrm{t}-5.36748, \mathrm{p}$-value $<.00001$ in pre and post-tests. $85.5 \%$ of the boys had access to mobile phones. It was found that 93 (70.9\%) of the participants were underweight. Thirty four $(25.9 \%)$ were anaemic.

Conclusion: The present study has shown that workshops through effective module for adolescent boys are helpful in creating awareness amongst them. Therefore there is a need to address more and more adolescent boys with such kind of workshops.

Keywords: Adolescents Boys, Workshop, Knowledge Score

\section{Introduction}

WHO defines 'Adolescents' as individuals in the 10 to 19 years age group. ${ }^{1}$ Adolescents number 1.2 billion in the world today, making up 16 per cent of the world's population. Population of adolescents as a proportion of the total population, by region, 2018 , is $19 \%$ in South Asia. ${ }^{2}$ India has the largest population of adolescents in the 
world 253 million. ${ }^{3}$ Adolescence is the period of growing up: from a child to maturity; this phase is characterized by marked and rapid changes: physical, psychological, sexual, socio-economical. By helping adolescents realize their rights to health, wellbeing, education and full and equal participation in Society, we are equipping them to attain their full potential as adults. ${ }^{4}$ Though they are apparently healthy individuals, their health status is the predictor of that of the adult period in future.

Adolescents in India face multiple concerns: mental health problems, early pregnancy and childbirth, Human Immunodeficiency Virus/ Sexually Transmitted Infection (HIV/STI) and other infectious diseases, violence, unintentional injuries, malnutrition and substance abuse. ${ }^{5}$ These problems if not discussed and resolved at an early stage, could take serious form in their lives and create complications in adolescence

In Indian societies certain topics are considered taboo and life skills education does not take an important part in most of the homes and institutions. Thus, the adolescents are left of their own to deal with their issues. As they look up to the peers or other means to resolve such issues, they are prone to get misguided or devoid of credible knowledge. This affects their lifestyle too, as adolescents are fast learners and they adopt things quickly from the surroundings, their knowledge-attitude-behaviour depend on the resources and guidance they have got.

A 2018 study conducted in the same area where we have done the study, showed that out of 384 adolescent boys, $64 \%$ had overall knowledge about secondary sexual characters, 91\% had had knowledge about the methods of population control, $86 \%$ of them had partial knowledge and $14 \%$ had no knowledge at all about the names of STDs. Regarding prevention of STDs, majority of them (61\%) had partial knowledge, $36 \%$ had no knowledge whereas only $3 \%$ had good knowledge of prevention from STDs. ${ }^{6}$ The adolescent boys are also prone to substance abuse as they get introduced to such things by peers. A study showed that $32.7 \%$ adolescent male gave history of addiction in an urban slum in Andhra Pradesh, another study in an urban slum in Assam showed 35\% boys were current users of such products. ${ }^{7}$ Thus, these children who get addicted to such substances at this early age, continue to do so in adulthood also, which potentially affects their studies, career prospect, family relations, marital life, finance and value system.

Due to various socio-economic and health reasons, malnutrition is still prevalent in India and the youth is no exception to that. The young children in urban slums are particularly vulnerable to malnutrition not only due to poor financial condition of the families but also due to lack of knowledge about cheap and nutritious food items and food habits. The concerns of the adolescents in India are multi-faceted and it is certain that they are in the need of friendly and informative guidance regarding these issues.

To bridge the gap between the adolescents and adults including parents, nothing could be better than effective communication. This facilitates the adolescents talk about their experiences, doubts, expectations, fears without hesitation or worries of being humiliated. There are a couple of such methods that indirectly or directly promote them to talk, as summarized by Deccan Herald. Questions Box activity, where the participants can write any question on a piece of paper without mentioning the names, Group discussion, Painting, Poster or Essay competition, Quiz or Workshops that is based on themes related to adolescence. ${ }^{8}$

The Community Health Department (CHD) of a Tertiary Care Hospital in Delhi conducts Adolescent Boys Workshops in its field practice area, This study is aimed to find out the increase in the awareness and knowledge of adolescent boys who attend these workshops, on various adolescence related topics.

\section{Material and Methods}

Study Nature: It is a retrospective study.

Study Area: A resettlement and slum community located in North-East District of Delhi which is the field practice area of CHD.

Study Period: The study was conducted from $15^{\text {th }}$ February 2020 to $15^{\text {th }}$ May 2020.

Study Participants: A total of 131 adolescent boys (age group $10-19$ years)

\section{Inclusion Criteria}

- $\quad$ Residents of Sunder Nagari

- Boys between 10 to 19 years of age group

- Who gave the verbal consent to participate

\section{Exclusion Criteria}

- Boys $<10$ years of age

\section{Study Instrument}

A questionnaire: A structured pre-tested questionnaire comprised of five basic questions written in Hindi language, in multiple choice questionnaire (MCQ) style where the participants were expected to mark the right answer among the four choices given for each question. Each question would score a maximum of 2 marks thus making it a total of 10 marks. The questions were on the age group for adolescence, legal age of marriage, Nutrition, HIV/AIDS and Social media. While the pre-test was to assess the existing knowledge of the participants, the post-test was aimed at assessing the retention of knowledge after the sessions.

Adolescent Boys' Workshop Module: A module had already 
been prepared to conduct these workshops. The topics covered in this module are physical, mental and sexual growth during adolescence, Nutritional deficiency and Anaemia, STDs, HIV/AIDS, Positive usage of time and Social media.

\section{The Adolescent Boys Workshops}

The participants were voluntarily called to join the workshops five times between February - August 2019. Basic demographic details of the participants were taken at the time of registration. Their health and family history of diseases was noted. The whole group was addressed by a facilitator, who told about the purpose of workshop.

They were given Pre-test questionnaire. In the workshop 4 to 5 facilitators took different topics with the help of colourful and informative module designed for adolescent boys, through interactive talk and question \& answer session. Each workshop lasted for 3 hours. The same questionnaire was used after the workshop to assess the retention of knowledge about common adolescent issues.

Each participant under-went health check-up after the workshop. The participants' height, weight, BMI, were measured. Anaemia was assessed clinically and those found to be moderately anaemic were sent for $\mathrm{Hb}$ Test. This test was done at CHD Medical lab.

\section{Statistical Analysis}

All the data of five workshops was entered in MS excel sheet. This data contained 1. number of participants present, their age, religion and availability of a mobile phone at home, participants' past and present history of health concerns; 2. Pre-test and post-test scores; The scores ranged from a low of 0 to a maximum of $10 ; 3$. Their health check-up details such as height, weight and BMI were also entered. Clinically anaemic participants' $\mathrm{Hb}$ test report was entered.

Statistical analysis was done with the help of socscistatistics. $\mathrm{com} /$ tests, in order to obtain mean, median and mode of the test scores. Percentages were calculated for obtaining demographic details, and the student $T$ test was applied to find the statistically significant $p$ value. A $p$-value $<0.05$ was taken as significant.

\section{Ethical Issues}

The study being a retrospective study, did not require clearance from Institutional Ethics Committee. Besides, informed verbal consent of the participants was taken before eliciting information from each participant.

\section{Result}

Total number of participants in five workshops was 131. They were divided into early, middle and late adolescent age groups and religion-wise. As the table shows, most of the boys were in early adolescence. Nearly equal number belonged to two religions. It was also observed that availability of a mobile phone was present for 112 (85.5\%) boys (Table 1 ).

Table I.Socio-demographic details of participants

\begin{tabular}{|c|c|c|}
\hline & No. & \% \\
\hline Age Group & & \\
\hline 10 to 14 & 100 & 76.3 \\
\hline$>14$ to 17 & 23 & 17.6 \\
\hline$>17$ to 19 & 8 & 6.1 \\
\hline & 131 & 100.0 \\
\hline Religion & & \\
\hline Hindu & 65 & 49.6 \\
\hline Muslim & 66 & 50.4 \\
\hline & 131 & 100.0 \\
\hline Mobile Phone & & \\
\hline Available & 112 & 85.5 \\
\hline Not available & 19 & 14.5 \\
\hline & 131 & 100.0 \\
\hline
\end{tabular}

Pre-test and Post-test questionnaire were filled up by all the participants. The level of knowledge score of participants about Adolescence showed marked improvement i.e. in pre-test 74 (56.5\%) and in post-test 104 (79.4\%) scored 6 and more out of 10 marks. The mean pre-test score of $5.3 \pm 2.812$ showed highly statically significant improvement in post-test mean $=7.0 \pm 2.596 ;$; $\mathrm{t}$ " $-5.36748 . \mathrm{p}<.00001$ after the workshop (Table 2).

Table 2.Pre-test and Post-test Marks and Percentages

\begin{tabular}{|c|c|c|c|c|c|}
\hline \multicolumn{3}{|c|}{ Pre-test } & \multicolumn{3}{c|}{ Post-test } \\
\hline Marks & No. & $\%$ & Marks & No. & $\%$ \\
\hline 0 & 10 & 7.6 & 0 & 3 & 2.3 \\
\hline 2 & 22 & 16.8 & 2 & 10 & 7.6 \\
\hline 4 & 25 & 19.1 & 4 & 12 & 9.2 \\
\hline 6 & 34 & 26.0 & 6 & 31 & 23.7 \\
\hline 8 & 30 & 22.9 & 8 & 41 & 31.3 \\
\hline 10 & 10 & 7.6 & 10 & 34 & 26.0 \\
\hline & 131 & 100.0 & & 131 & 100.0 \\
\hline
\end{tabular}

It was found that only 38 (29.0\%) of adolescent boys were healthy, 66 (50.4\%) were underweight and 27 (20.6\%) were severely underweight (Table 3).

In the health check-up, it was found that 34 (26\%) boys were anaemic clinically and by laboratory test. Seven (5.3\%) had haemoglobin level between 8 to 9 gm\% only. (Table 4) 
Table 3.Health status of the participants

\begin{tabular}{|c|c|c|}
\hline Nutritional status & No. & \% \\
\hline Normal & 38 & 29.0 \\
\hline Underweight & 66 & 50.4 \\
\hline Severe Underweight & 27 & 20.6 \\
\hline & 131 & 100.0 \\
\hline
\end{tabular}

Table 4.Results of hemoglobin test done in participants

\begin{tabular}{|c|c|c|}
\hline Anemia & No. & $\%$ \\
\hline Not anemic clinically & 97 & 74.0 \\
\hline $\begin{array}{c}\text { 12 - 14 gm. \% (by testing with } \\
\text { Haemoglobinometer) }\end{array}$ & 8 & 6.1 \\
\hline$>9$ to 12 gm. $\%$ & 19 & 14.5 \\
\hline 8 to 9 gm. $\%$ & 7 & 5.3 \\
\hline & 131 & 100.0 \\
\hline
\end{tabular}

It was noted that $5(3.8 \%)$ of adolescents were addicted to tobacco. Some 13 (9.9\%) had past history of illnesses in last six months and there was a family history of noncommunicable diseases (NCD) in 20 (15.3\%) (Table 5).

Table 5. History of addiction, illnesses in participants and in their families

\begin{tabular}{|c|c|c|}
\hline History & No. & $\%$ \\
\hline $\begin{array}{c}\text { Addiction to tobacco (chewing \& } \\
\text { smoking) }\end{array}$ & 5 & 3.8 \\
\hline Past history of illness & 13 & 9.9 \\
\hline $\begin{array}{c}\text { Family history of non-communicable } \\
\text { diseases }\end{array}$ & 20 & 15.3 \\
\hline
\end{tabular}

Note: One of the boys had tuberculosis

\section{Discussion}

Literature is full of workshops held for girls but our study was focussed on adolescent boys. Some schools have had sessions for young boys: on mental, psychological and social issues in Gurgaon in two slots for classes VI to VIII and IX to $X$ on two different days. ${ }^{9}$ A UNICEF article aptly states that there should be more involvement of men as well as young boys in projects and programmes to get the desired outcome. ${ }^{10}$

Our study was aimed to find out the increase in the awareness and knowledge on various adolescence related topics, for adolescent boys who attended workshops. It showed that mean knowledge score went from $5.3 \pm 2.812$ to $7.0 \pm 2.596$ (" $\mathrm{t}$ " $-5.36748 . \mathrm{p}<.00001)$ in pre and posttests. In a study on adolescent boys on pubertal changes in selected high school of Udupi District the mean knowledge score went from 16.96 \pm 3.816 . to $24.05 \pm 3.036$ ( $" \mathrm{t} "=14.352$, $\mathrm{P}<0.05) .{ }^{11}$

In a study done by Ericsson, it was found that $\mathbf{3 0}$ million urban pre-teen and teens have active mobile usage, $20 \%$ of them being between 9-11 years of age. ${ }^{12}$ In our study, 112 (85.5\%) boys had active mobile phones in family.

A study in the slums of Mumbai found $46.6 \%$ boys were severely underweight and $26.0 \%$ were underweight. ${ }^{13} \mathrm{We}$ found that 27 (20.6) \% of the participants were severely underweight, 66 (50.4\%) were underweight. This means that adolescent in our area are better off in comparison to Mumbai slum.

In India, 18 per cent of boys are anaemic. ${ }^{14}$ In our study the per cent of anaemic boys was 19.8. Among anaemic, 7 (5.3\%) had $\mathrm{Hb}$ between 8-9 gm/dl and 19 (14.5\%) between $>9$ to $12 \mathrm{gm} / \mathrm{dl}$ which is again lesser than the south India slum study showing $36.1 \%$ subjects having $\mathrm{Hb} 10 \mathrm{gm} / \mathrm{dl}$ or less. ${ }^{15}$

In two different studies in urban slums in India, there was $49.5 \%$ and $32.7 \%$ prevalence of addiction among adolescent boys in central and south India respectively. ${ }^{16,17}$ In our study, however, the history of addiction was noted in only 5 (3.8\%). Our study is comparable to the finding of $2.2 \%$ in an urban school in Gujarat. ${ }^{18}$ This difference in the first two and the last two studies could be due to non-disclosure because of lack of privacy in a workshop and/ or due to fear of letting their family members know about it.

It is well known that family history is a predictor and nonmodifiable risk factor for NCDs. ${ }^{19}$ In this study, 20 (15.3\%) participants gave family history of hypertension, diabetes or dual disease.

\section{Conclusion}

We have come to an understanding that our thought process is skewed towards adolescent girls - more adolescent girls' workshops. Less importance is given to the opposite sex.

The present study has shown that workshops through effective module for adolescent boys are helpful in creating awareness amongst them. Therefore there is a need to address more and more adolescent boys with such kind of workshops. The authors encourage other Government Organizations as well as NGOs to replicate this kind of effort.

\section{Acknowledgement}

The authors are thankful to all the facilitators and participants of Adolescent Boys Workshops, held in the Community Health Department.

\section{Sources of Funding: None \\ Conflicts of Interest: None}




\section{References}

1. National Health Portal of India. Adolescent Health, 2016. Available from: https://www.nhp.gov.in/healthlyliving/ adolescent-health-10-19-years accessed on 27.04.2020

2. UNICEF. Investing in a safe, healthy and productive transition from childhood to adulthood is critical. Adolescents overview 2019. Available from: https:// data.unicef.org/topic/adolescents/overview/ accessed on 02.05.2020.

3. Ministry of Health and Family Welfare, Govt. of India. Strategy Handbook. Rashtriya Kishor Swasthya Karyakram. Adolescent Health Division 2014 accessed on 27.04.2020.

4. United Nations. The Global Strategy for Women's, Children's and Adolescents' Health (2016-2030) 2015. Available from: http://www.who.int/life-course/ partners/global-strategy/globalstrategyreport20162030-lowres.pdf accessed on 02.05.2020

5. Sivagurunathan C, Umadevi R, Rama R, Gopalakrishnan S. Adolescent health: present status and its related programmes in India. Are we in the right direction? Journal of clinical and diagnostic research: JCDR 2015; 9(3): LE01-6. DOI:10.7860/ JCDR/2015/11199.5649 accessed on 30.04.2020.

6. Harshana AKS, Kapoor SK. A Study of Knowledge of Adolescent Boys of Urban Slum of Delhi regarding Development of Secondary Sexual Characters. Indian Journal of Youth and Adolescent Health 2018; 5(1): 1-29. 10.24321/2349.2880.201803 accessed on 27.04.2020.

7. Bardhan T, Saikia AM, Baruah R. Substance use among adolescents living in slums of Guwahati city, Assam: A growing public health concern. International Journal of Medicine and Public Health 2015; 5(4): 279-282. Available from: http://ijmedph.org/article/397 accessed on 30.04.2020.

8. Nagaraju KL. Adolescent Awareness, Deccan Herald. Available from: https://www.deccanherald.com/ content/520366/adolescent-awareness.html accessed on 30.04.2020.

9. Workshop for Adolescent Boys, Meenakshi Public School. Available from: https://www.meenakshipublicschool. com/event/workshop-adolescent-boys accessed on 01.05.2020.

10. Gaag Nvd. The importance of working with boys in closing the adolescent gender gap, UNICEF. Available from: https://www.unicef-irc.org/article/1151-theimportance-of-working-with-boys-in-closing-theadolescent-gender-gap.html accessed on 01.05.2020.

11. Shetty AK, George AP, Beena KJ, Kabiraj T, Paul B, Raj $A A$ et al. Effectiveness of planned teaching programme on knowledge regarding pubertal changes among adolescent boys in selected high school of Udupi District. Nitte University Journal of Health Science
2016. available from: http://nitte.edu.in/journal/ june2016/10o.pdf accessed on 02.05.2020.

12. Jha N. 21 percent Kids in India hooked on to mobile internet: Study, The Mobile Indian, New Delhi. available from: https://www.themobileindian.com/news/21percent-kids-in-india-hooked-on-to-mobile-internetstudy-6430 accessed on 02.05.2020.

13. Rode S. Prevalence of Malnutrition among Adolescent: The Socio-Economic Issues and Challenges in Mumbai Metropolitan Region. Global Journal of Human Social Science 2015; 15: 13-22. Available from: https:// globaljournals.org/GJHSS_Volume15/E-Journal_ GJHSS_\%28C\%29_Vol_15_Issue_5.pdf accessed on 30.04.2020.

14. UNICEF. Adolescent Nutrition. Available at https://www. unicef.org/india/what-we-do/adolescent-nutrition accessed on 30.04.2020.

15. Yerpude PN, Jogdand KS. A Cross Sectional Study of Socio-demographic Determinants of Anaemia in Adolescent Boys of Urban Slum Area in South India. International Journal of Medical Research \& Health Sciences 2013; 2(3). Available from: https://www. ijmrhs.com/medical-research/a-cross-sectional-studyof-sociodemographic-determinants-of-anaemia-inadolesecent-boys-of-urban-slum-area-in-south-indi. pdf accessed on 02.05.2020.

16. Sarangi L, Acharya HP, Panigrahiet O. Substance abuse among adolescents in urban slums of Sambalpur. Indian journal of community medicine: official publication of Indian Association of Preventive \& Social Medicine 2008; 33(4): 265-267. DOI: 10.4103/0970-0218.43236 accessed on 02.05.2020.

17. Kokiwar PR, Jogdand GR. Prevalence of substance use among male adolescents in an urban slum area of Karimnagar district, Andhra Pradesh. Indian Journal of Public Health 2011; 55(1). Available at http://www.ijph. in/article.asp?issn=0019557X; year=2011; volume=55;issue $=1$;spage $=42$;epage $=45$; aulast $=$ Kokiwar.

18. Puwar T, Saxena D, Yasobant S, Savaliya S. Noncommunicable Diseases among School-going Adolescents: A Case Study on Prevalence of Risk Factors from Sabarkantha District of Gujarat, India. Indian J Community Med 2018; 43(Suppl. 1). Available from: https://www.ncbi.nlm.nih.gov/pmc/articles/ PMC6324039/ accessed on 02.05.2020.

19. Centre for Disease Control. Overview of Noncommunicable Diseases and Related Risk Factors. Available from: https://www.cdc.gov/globalhealth/ healthprotection/fetp/training_modules/new-8/ Overview-of-NCDs_PPT_QA-RevCom_09112013.pdf accessed on 02.05.2020. 